\title{
Três textos sobre a violência
}

\author{
Norberto Bobbio \\ Traduçáo de GIACOMINA FALDINI \\ e apresentação de CELSO LAFER.
}

Na preparação do dossiê sobre a violência, o Conselho Editorial da Revista USP achou importante incluir algo da reflexão de Norberto Bobbio sobre o assunto. A escolha recaiu em três artigos da década de 80 , escritos para o jornal La Stampa e recolhidos no livro de Bobbio, L'utopia capovolta, de 1990, que integra a coleção La Stampa - Terza Pagina, que objetiva reunir, em volumes, o mais relevante dos escritos jornaltsticos de seus grandes colaboradores. Os três artigos de Bobbio, na cuidadosa tradução de Giacomina Faldini, bibliotecária da Faculdade de Direito da USP, estão sendo publicados neste número com a sua autorização, que muito agradecemos.

Trata o primeiro, "Atratdos pela direita", de 2/11/1982, dos diversos matizes da esquerda e da direita, e dos componentes autoritários, libertórios, igualitários e não-igualitários que os caracterizam e diferenciam. Trata o segundo, "A violência obscura", de 27/12/1984, da violência terrorista e da relação entre meios e fins, vista pelo ângulo da ética política, que deve conjugar princtpios e resultados. É com base nesta perspectiva que Bobbio, na sua crítica à violência terrorista, qualifica como imoralidade absoluta a açâo perversa cujo objetivo é o de fazer uma perversidade. Finalmente o terceiro, "É licito matar o tirano?", de 21/9/1986, tomando como ponto de partida de análise o atentado a Pinochet no Chile, retoma este clássico tema da discussão política.

\section{atraídos Pela Direita}

Na recente convenção sobre a nova direita, que teve lugar em Cuneo, por iniciativa do Instituto Histórico da Resistência, alguém colocou em dúvida o fato de que "direita" e "esquerda" sejam ainda conceitos adequados para representar as divisões atuais entre doutrinas e movimentos políticos. Fomos convidados a refletir sobre o fato de que a esquerda esteja redescobrindo escritores de direita como Carl Schmitt e que a direita, particularmente a nova direita reacionária, se interesse por escritores de esquerda, como Gramsci. Naqueles mesmos dias, numa entrevista à revista "Panorama", Massimo Cacciari, intelectual de esquerda, declarava discordar "daquele conceito rígido de política que prevê uma direita e uma esquerda entendidas como blocos compactos e diametralmente opostos um ao outro".

$\mathrm{Na}$ realidade, esta confusão não é nova, nem injustificada: extrema esquerda e extrema direita possuem amores diferentes, mas ódios comuns. Um destes ódios é a democracia, entendida como o regime no qual as únicas decisões legítimas são aquelas coletivas, tomadas com base na opinião da maioria. Por outro lado, as razões desta aversão são, para cada bloco, opostas. Justamente levando em consideração essas razões
NORBERTO BOBBIO é filosófo italiano. Tem publicado no Brasil os seguintes livros: Qual o socialismo? e Estado, governo e sociedade (Editora Paz e Terra), Conceito de sociedade civil (Ediçōes Graal). Teoria do ordenamento politico (Editora da Universidade de Brasnia) e Teoria do ordenamento jurídico (co-edição UNB/Polis) 
opostas é que conseguimos captar, ainda hoje, a principal característica distintiva dos dois blocos nos quais se divide, tradicionalmente, o universo político.

A oposição consiste no seguinte: para a extrema esquerda, a regra da maioria, na qual cada cidadão vale um voto, assegura uma igualdade puramente formal, mas não consegue, de igual maneira, promover a igualdade substancial; para a extrema direita, a mesma regra da maioria, nivelando ainda que formalmente todos os cidadãos, acaba por desconhecer o fato de que os homens são, substancialmente, desiguais. Como vemos, a divisão acontece por causa de um juízo diferente que ambas as partes fazem da igualdade e da desigualdade como um ideal a ser atingido. Este juízo diferente permite diferenciar ideologias que tendem a se igualarem, em relação à democracia formal, ideologias que chamarei de igualitárias, e ideologias que demandam uma maior desigualdade, sempre em relação à democracia formal, e que chamarei de "desigualitárias".

Trata-se de uma distinção tão velha quanto o universo, muito mais antiga do que a distinção entre esquerda e direita, que remonta à Revolução Francesa. Mas, desde que os dois termos, esquerda e direita, foram introduzidos na linguagem política, eles foram sempre usados para indicar a diferença entre ideologias partidárias da igualdade e ideologias partidárias da desigualdade. Portanto, enquanto existirem doutrinas e movimentos antagônicos com base no oposto valor dado ao princípio da igualdade, o uso dos dois termos é não só legítimo mas também útil. A sua negação é a prova de uma imperdoável ignorância ou, pior ainda, da ilusão de apagar, juntamente com os dois termos, a realidade que eles designam.

\section{Desde que os dois termos, esquerda e direita, foram introduzidos na linguagem política, eles foram sempre usados para indicar a diferença entre ideologias partidárias da igualdade e ideologias partidárias da desigualdade}

A contraposição entre igualdade e desigualdade é tão antiga quanto o universo, pelo simples fato de que os homens são, ao mesmo tempo, iguais e desiguais. São iguais pois pertencem ao gênero humano, distinto dos outros gêneros, por exemplo, aquele dos animais; mas são desiguais, se considerados como indivíduos, um a um. As ideologias igualitárias acentuam, em primeiro lugar, o fato de que todos os homens pertencem ao gênero humano; as ideologias partidárias da desigualdade acentuam as visíveis e irrefutáveis diferenças que existem entre os indivíduos. Em outras palavras, as primeiras dão mais importância ao que nos une; as segundas salientam o que nos divide.

Entre as várias provas históricas que podemos fornecer a respeito desta contraposi-

ção, limito-me a salientar aquela que podemos extrair dos dois autores que, com todo o direito, são considerados os principais inspiradores dos dois blocos: Rousseau e Nietzsche. No seu "Discurso sobre a origem das desigualdades entre os homens", Rousseau parte da constatação de que os homens nascem fundamentalmente iguais, mas que a civilização corrompida os torna desiguais. Nietzsche, ao contrário, parte da constatação de que os homens são por natureza desiguais e que somente a civilização, com a sua moral igualitária, cujo principal responsável é o Cristianismo e da qual, no presente momento, a democracia e o socialismo são uma manifestação, a civilização os torna injustamente iguais.

$O$ ideal que pode ser extraído da interpretação rousseauniana do curso histórico é o ideal revolucionário da demolição das sociedades históricas, fundadas na desigualdade social e da instauração de uma nova sociedade na qual todos os cidadãos tenham os mesmos direitos. $O$ ideal que pode ser extraído da interpretação nietzschiana, ao contrário, é o ideal reacionário da restauração de uma ordem hierárquica, cuja destruição causou o triunfo da quantidade, do "rebanho".

O próprio Nietzsche refere-se seguidamente a Rousseau, o seu grande inimigo, toda vez que extravasa seu grande furor contra o princípio da igualdade e contra aquele acontecimento histórico, a Revolução Francesa, que teria tentado alcançar esta igualdade: "O que odeio - diz em uma citação entre tantas - é a rousseauniana moralidade da Revolução Francesa... A doutrina da igualdade. Não existe tóxico mais venenoso!'.

Alguem poderá objetar que o critério da igualdade não é o único que permite caracte- 
rizar duas ideologias opostas. Há também o critério da liberdade, com base no qual podemos distinguir ideologias libertárias e autoritárias. Respondo que este critério serve para distinguir, no âmbito da esquerda e da direita, a ala extremista da ala moderada. Podemos, de fato, sustentar que as duas alas extremistas são autoritárias e as alas moderadas são libertárias.

Conseqüentemente, a linha sobre a qual estão colocadas as várias ideologias, partindo da esquerda em direção à direita, desenrola-se através destas quatro áreas. Na extrema esquerda estão os movimentos que são, ao mesmo tempo, igualitários e autoritários: o exemplo clássico é o dos jacobinos e de seus tardios seguidores, os bolcheviques. À esquerda moderada pertencem os movimentos igualitários e libertários: nos tempos atuais, o exemplo é constituído pelos partidos social-democráticos, que cobrem uma vasta área que poderia oportunamente chamar-se de "socialismo liberal". Em seguida, encontram-se os movimentos da direita moderada, que são ao mesmo tempo libertários e não-igualitários. E, finalmente, há a extrema direita, à qual pertencem os movimentos que juntam o autoritarismo ao desejo (ou nostalgia) de uma sociedade ordenada hierarquicamente.

Com certeza, a realidade é mais rica do que qualquer esquema. Porém, é sempre melhor um esquema qualquer do que a confusão mental da qual só podem derivar comportamentos politicamente aberrantes.

\section{A ViolênCIa ObSCURA}

O ano termina, em nosso país, sob o signo da violência mais abjeta. Fico cada vez mais convencido de que a violência terrorista, em especial aquela dirigida não contra um personagem representativo de um poder que se deseja abater, mas aquela que se desencadeia contra uma multidão ignara, escolhida ao acaso, com uma indiferença absoluta, esta violência terrorista seja uma violência que tem fím em si mesma. A violência pela violência. Ou, pelo menos, a enorme desproporção entre o meio e o fim é tal que nenhuma pessoa razoável consegue aplicar a um tal ato a máxima maquiavélica do fim que justifica os meios.

Esta máxima fundamental da ética política, e não somente da ética política mas de toda ética que julgue a ação, qualquer ação, não com base em princípios universais mas com base nos resultados, esta máxima, para ser aceita, exige três condições.

Em primeiro lugar: nem todo fim justifica qualquer meio. $O$ fim que justifica o meio deve, por sua vez, ser justificado. Em outras palavras, deve ser um fim bom. Contudo, com que critério podemos distinguir os fins bons dos fins maus? E a quem cabe julgar se um fim é bom ou mau? A máxima maquiavélica deixa esse problema completamente aberto. A ética dos resultados remete para a ética dos princípios, em um círculo sem fim.

Em segundo lugar: o fim não somente deve ser, de alguma maneira, justificável, mas também deve ter uma certa probabilidade de ser alcançado. No drama de Camus, um dos personagens, o revolucionário, declara: "Nós matamos para construir um mundo onde ninguém mais matará", aplicando a máxima segundo a qual o fim justifica os meios e anunciando um fim que não pode não ser reconhecido universalmente como moralmente nobre. Porém, a sua companheira interrompe-o: "E se isso não acontecer?" Quantas vezes, na História, uma ação moralmente reprovável não foi realizada, com a intenção de alcançar um objetivo nobre, mas, depois, "não foi assim?".

Em terceiro lugar: admitindo que o fim seja nobre, o que significa dizer que ele possa ser justificado através de argumentos de natureza ética e passível de ser alcançado, com uma certa probabilidade, o que significa também que ele não é arbitrário nem inconseqüente, nem ingenuamente utópico, os meios empregados devem ser tais de forma a presumir, com base no senso comum, que eles sejam adequados ao fim e se, com base nesse mesmo senso comum, são julgados imorais, devem ser também os únicos meios capazes de alcançar aquele objetivo e, portanto, devem ser não somente oportunos mas também rigorosamente necessários.

Em um ato terrorista como aquele efetuado na noite do domingo, 23 de dezembro*, nenhuma destas três condições é encontrada. Em primeiro lugar, qual é o fim? Impossível o juízo sobre a bondade ou não do fim, se não sabemos exatamente qual seja o fim declarado ou presumido. Geralmente, no ato de terrorismo puro o fim não é declarado: ao contrário do terrorista que atinge um alvo preciso, o terrorista cujo objetivo seja unicamente o de semear o pânico numa multidão indefesa pode reivindicar o gesto, mas
* Exirafdo de Stampa Sera, 24 de dezembro de 1984: "Um outro gravíssimo episódio transtornou a consciencia dos italianos, apos decorridos dez anos do atentado do trem Italicus. Uma tragédia nacional que parece ser a repetiçăo identica daquele terrivel momento. Uma tremenda explosão aconteceu ontem, por volta das 19 horas, no trem rápido 904 Nåpoles-Roma-Milăo (que tinha partido as 12 h55 o deveria (que (a) gar as 22 horas), composto de quatorze vagós e que transportava mais de seecentas pessoas (em sua maioria turistas); e justamente no mesmo túnel, entre Florença e Bolonha, com 18 quilometros de comprimento, no qual os terroristas 'negros', no dia 4 de agosto de 1974, haviam provocado a morte de doze doze pessoas e terimentos em outras quarenta e oito. O atentado foi reivindicado por diversas organizaçóes de extrema direita e de extrema esquerda".

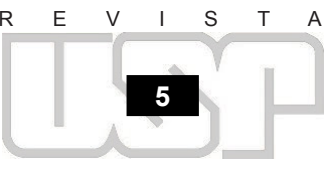




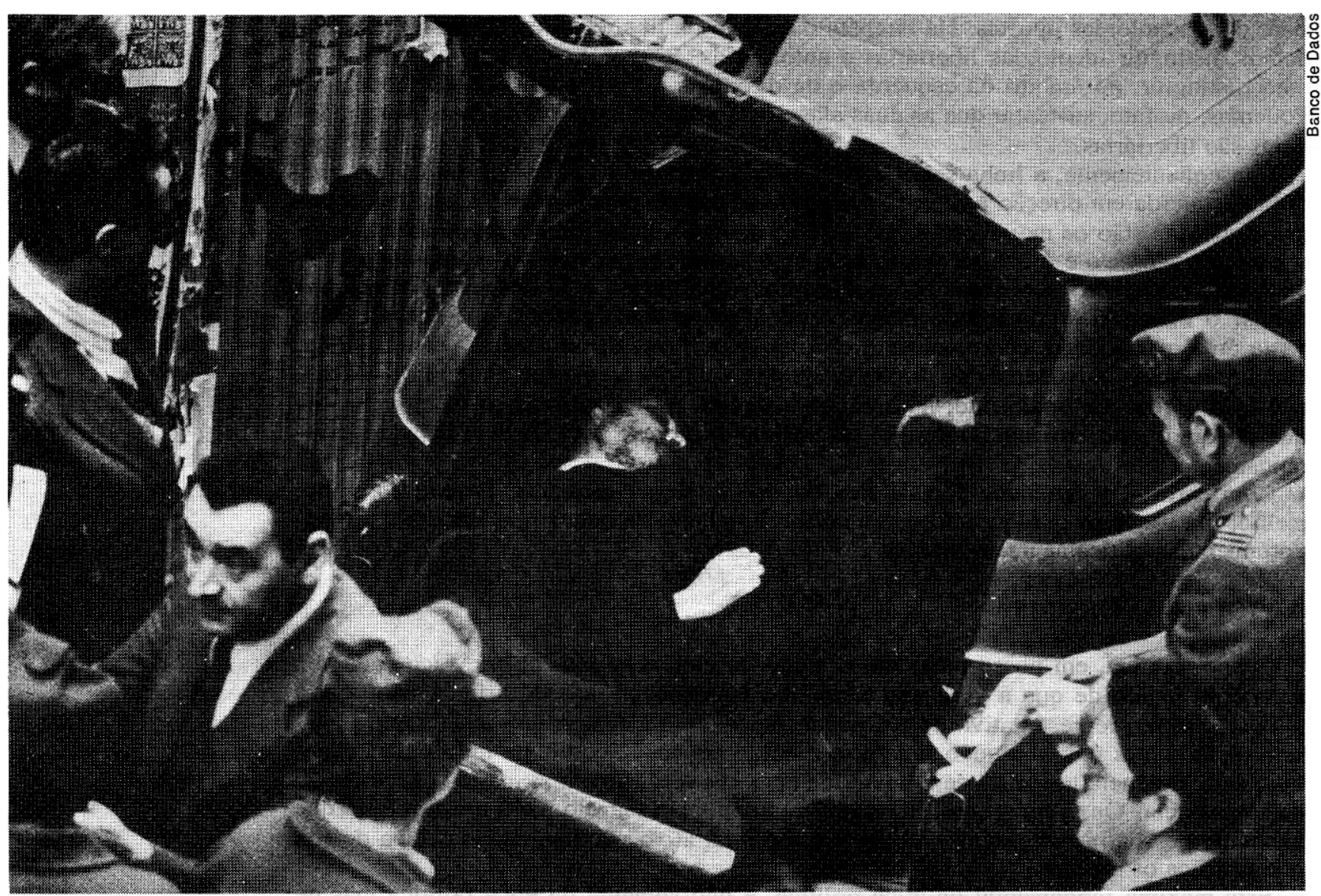

Aldo Moro, Primeiro Ministro italiano, morto pelo grupo terrorista Brigadas Vermelhas não revela nunca seu objetivo. Para dar uma aparência de justificativa racional a esta forma de terrorismo, acreditou-se, a partir da matança da praça Fontana, que existisse um fim mais ou menos preciso, mas real (e, neste sentido, podemos falar em fim presumível) e que consistia na criação de uma atmosfera à qual foi dado um nome: desestabilização. Contudo, o que significa "desestabilizar"? Trata-se de uma das várias palavras da linguagem política que, habitualmente utilizadas na conversação cotidiana, acabamos por nos convencer de que têm um significado preciso, ao passo que, quando tentamos defini-las, percebemos que são móveis, fluidas, impossíveis de alcançar. Experimentemos definir "desestabilização" como o fato de provocar, num contexto social, um estado de confusão tal que seja praticamente impossível o normal funcionamento de um sistema político, qualquer que ele seja (pois não podemos dizer que somente os regimes democráticos possam ser objeto de uma ação desestabilizadora). Porém, este fim é passível de ser alcançado?

Que uma matança, ainda que enorme, em um ponto isolado do território nacional, especialmente de um território vasto como aquele italiano, possa ter conseqüências capazes de criar condições para uma reviravolta com força de mudar radicalmente a situação vigente, é pouco provável. Aliás, as matanças realizadas até agora não tiveram outro resultado senão o de semear o pânico, aumentar a indignação das pessoas, provocar lutos cujas conseqüências na esfera privada são infinitamente superiores àquelas públicas e políticas. Os acontecimentos teriam se desenrolado diferentemente, no nosso país, se as matanças não tivessem acontecido? Teríamos tido governos mais estáveis, políticos menos discutíveis, maior ou menor inflação, maior ou menor desemprego? Neste caso, um terremoto não seria igualmente desestabilizador? Em um naufrágio não morrem igualmente vítimas inocentes?

Mas se a consecução do fim, até mesmo daquele fim presumido, é pouco provável, não deveremos deduzir disso que os meios (refiro-me à terceira condição) são francamente inadequados? As interpretações possíveis de uma tal ação são duas: ou o autor é irracional ou o meio foi convertido no fim, não tem um fim, porque é ele próprio o fim. Em relação à ação de terrorismo puro, inclino-me por esta segunda interpretação. $O$ único fim da matança é a própria matança. 
Sei muito bem de estar correndo sobre o fio do paradoxo, mas procuro compreender e fazer compreender o fato de que há açōes humanas frente às quais podemos falar em maldade absoluta. Se é verdade, como eu acredito que seja, que a moralidade absoluta consiste em fazer o bem, com nenhum outro objetivo a não ser o de fazer o bem, desinteressadamente, a imoralidade absoluta deverá consistir em realizar uma ação perversa, com nenhum outro objetivo a não ser o de fazer uma perversidade. $O$ terrorista que faz explodir uma bomba dentro de um trem tem perfeitamente consciência de que as vítimas atingidas são inocentes. Nem mesmo são suas inimigas. Nem são os bodes expiatórios de um rito propiciador, efetuado para aplacar um deus irado. São coisas sem valor, objetos sem utilidade (e por isso um vale o outro), cuja destruição ele confia ao acaso, para mostrar a sua cega vontade de poder, a sua radical indiferença em relação a qualquer fim que lhe seja transcendente.

\section{É LÍ́CITO MATAR O TIRANO?}

É lícito matar o tirano? Era natural que, após o atentado a Pinochet", mais uma vez a eterna questão fosse levantada, inclusive na Itália. Nestes últimos dias, a questão foi colocada, também, entre outros, por Rossana Rossanda, no "Manifesto", que respondeu de forma afirmativa, levantando, porém, as dúvidas de Adriano Sofri e de Mieli, na Stampa, e de Giuliano Zincone no Corriere della Sera.

O problema é antigo e as várias e possíveis soluçōes também. Para dar alguns exemplos, numa época em que as guerras de religião haviam favorecido o nascimento de doutrinas que pregavam o tiranicídio, Hobbes colocava a máxima "હ lícito matar o tirano" entre as teorias sediciosas que um Estado bem ordenado deveria proibir (na república de Hobbes, o artigo de Rossana Rossanda teria sido censurado e a autora talvez teria ido para a cadeia). Na época da Revolução Francesa, quando na catedral havia festas e ritos em honra de Brutus, Kant afirmou que qualquer pessoa com um mínimo de sentido dos direitos humanos não podia deixar de ter um "arrepio de horror" frente à execução solene de Carlos I da Inglaterra e de Luiz XVI da França.

Como todos os problemas morais, o problema da licitude do tiranicídio também não é de fácil solução. Aliás, não existe uma solução que possa ser dada e aceita de uma vez por todas, porque cada caso é diferente de todos os demais. A solução depende das circunstâncias de lugar e de tempo, da pessoa contra a qual o ato é dirigido, das pessoas que o realizam, da gravidade das culpas e da impossibilidade de recorrer a outras soluções. Tinham razão ou não os conspiradores que, no dia 20 de julho de 1944, tentaram matar Hitler? Tinha rãzão ou não o anárquico Bresci ao matar Humberto I? É suficiente fazer estas duas perguntas, e outras semelhantes poderiam ser feitas, indefinidamente, para percebermos que, sob o nome genérico de atentado, ou de ato terrorista, se escondem eventos totalmente diferentes, que não podem ser julgados com os mesmos parâmetros. O primeiro tinha uma finalidade preponderantemente liberatória, o segundo essencialmente punitiva.

O problema fica mais complexo quando atentarmos para o fato de que a mesma ação pode sempre ser julgada com dois critérios diferentes: ou com base em regras préconstiturdas, que devem ser obedecidas, ou com base nos resultados que devem ser atingidos. Estes dois juízos não coincidem quase nunca: observadas as boas regras, freqüentemente alcançamos resultados ruins; procurando obter bons resultados, muitas regras boas são consciente e tranqüilamente pisoteadas.

Se o atentado for julgado com base nas regras pré-constituídas, é claro que ele contraria a norma "não matar", que é uma das leis fundamentais da moral de qualquer povo e de qualquer tempo. E como tal deveria ser condenado. Porém, não há regra sem exceção. Não é lícito matar o inimigo numa guerra justa? Não foi sempre reco-

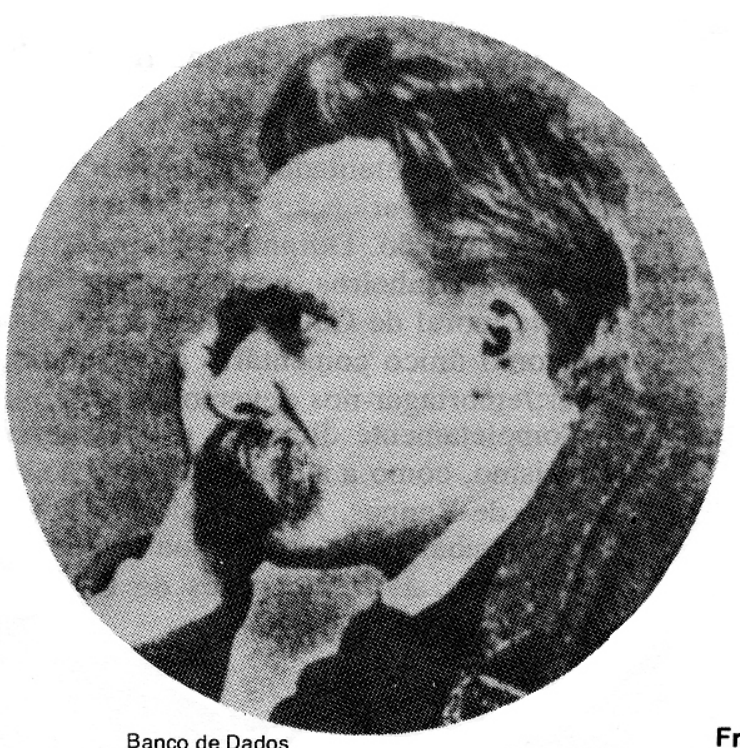

Friedrich Nietzsche atentado ao general Augusto Pinochet, ditador do Chlle, foi realizado por um comando de doze guerrilheiros, às 18:40 horas do domingo, dia $8 \mathrm{de} s \theta$ tembro de 1986. A açăo foi reivindicada pela Frente Patriótica Manuel Rodriguez. O general foi ferido ligeiramente em uma măo. 
O escritor argelino Albert Camus, em traço de Philippe Fellmer

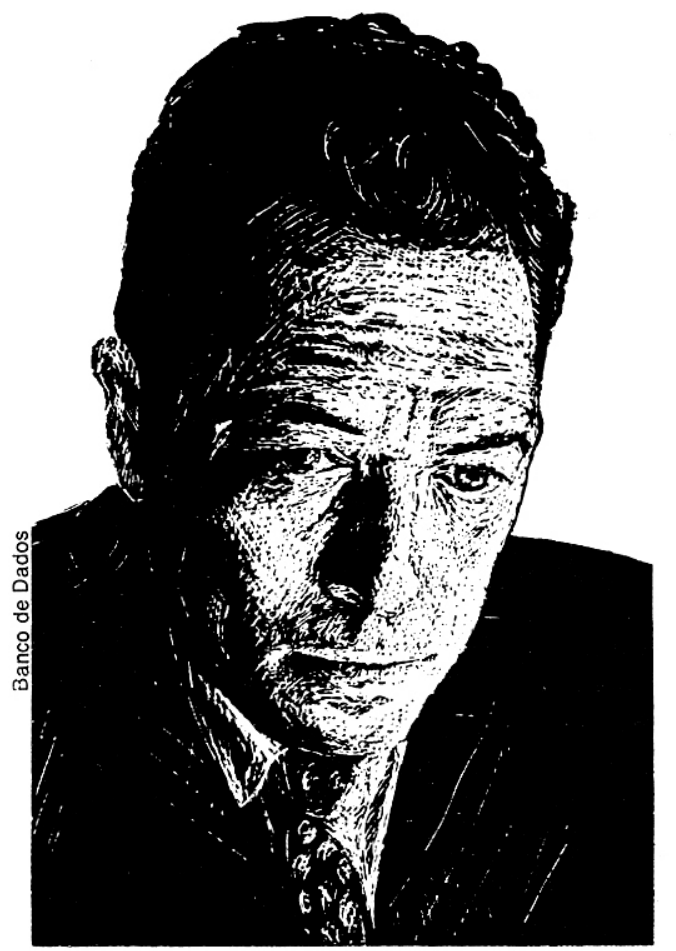

nhecida como justa a guerra de defesa? Não pode, pois, ser estendida ao tirano, considerado como inimigo interno, a exceção prevista para o inimigo externo?

Porém, como na guerra a exceção não pode existir frente à população civil, assim, aquele que praticar o atentado deveria golpear somente o tirano e não atingir as pessoas, o séquito ou os familiares que estejam perto dele. Atualmente, porém, esta condição é cada vez mais difícil de ser respeitada, devido ao tipo de armas empregadas, como demonstrou a morte de alguns guarda-costas, no atentado contra Pinochet. Isto torna a licitude do tiranicídio cada vez mais problemática, se julgada com base nos argumentos da filosofia pública tradicional. No drama $O s$ justos, de Camus, o conspirador, ao qual foi confiada a tarefa de assassinar o grão-duque, volta sem ter executado a ordem, porque na carruagem, perto do nobre, estavam sentados seus dois netinhos. Quando um dos companheiros o interpela, dizendo: "A Organização havia ordenado que você matasse o grão-duque", ele responde: "É verdade, mas não me mandou assassinar duas crianças".

Partindo do ponto de vista dos resultados, o juízo não fica nem mais fácil, nem mais claro. Em primeiro lugar, o resultado deve ser, senão seguro, pelo menos altamente provável. Não há dúvida de que, no caso do atentado ao general chileno, o resultado negativo contribuiu para reforçar o poder do ditador, seja em relação a todos aqueles cidadãos (que ainda são muitos) favoráveis a se livrarem da ditadura, em troca de uma democracia moderada, mas não a substituir o regime de Pinochet por um regime comunista; seja em relação aos Estados Unidos, que abandonarão completamente o general somente quando tiverem a certeza de que, em lugar de um governo democrático do tipo americano, não seja instituído um governo dirigido pelo partido comunista.

Em segundo lugar, devemos prever que o resultado seja não somente possível de ser alcançado com um alto grau de probabilidade, mas também que, se alcançado, seja tal que não deixe lugar a dúvidas quanto à sua conveniência ou oportunidade, no sentido de que, colocados nos pratos da balança o mal necessário e o bem possível, este segundo prevaleça. É inútil dizer quanto esta solução é difícil. No caso do atentado a Giovanni Gentile (sei que coloco o dedo sobre uma ferida amarga), a desproporção entre a morte de um homem e as conseqüências que esta morte podia ter, na conduta da guerra, era tal que nós hoje podemos ficar muito em dúvida a respeito do bom senso daquele ato (embora deva confessar que, naquela época, eu não me colocara o problema sob esse prisma).

No caso do atentado a Pinochet, suspendo o julgamento: parece-me estar cometendo um ato de prevaricação ao substituir com a minha opinião a daqueles que vivem dentro daquela situação. Durante a ocupação alemã, quando assistíamos à tortura e à morte de tantos companheiros, como eu teria julgado um atentado a Mussolini? Um homem da estatura moral de Calamandrei, à notícia da morte de Mussolini, transcreve no seu diário, como único comentário ao episódio, o famoso cântico de Alceu: "Agora devemos beber;/embriagar-nos devemos;/agora que Mirsilo morreu".

Completamente diferente e mais simples é o júzo sobre os atos indiscriminados do terrorismo, como a matança da estação de Bolonha, a da sinagoga de Istambul, a da loja da Rue de Rennes. A prova disso é que, frente ao atentado ao ditador chileno, nós nos interrogamos a respeito da sua licitude, ao passo que, frente àquelas carnificinas, ficamos horrorizados, incapazes de fornecer não somente uma justificação, mas também uma explicação plausível. 